\title{
Histopathological validation of high frequency epicardial echocardiography of the coronary arteries in vitro
}

\author{
A Kenny, C A Fuller, N R B Cary, L M Shapiro
}

\begin{abstract}
The accuracy and reliability of measurement of coronary artery dimensions and detection of atherosclerotic lesions by high frequency epicardial echocardiography were compared with histopathological results. Ten pressure perfused human hearts were examined in vitro with a $10 \mathrm{MHz}$ (Diasonics) transducer and a $7.5 \mathrm{MHz}$ (Vingmed/Sonotron) transducer. There was close agreement between ultrasound and pathological measurements of coronary artery luminal diameter. Qualitative changes in wall structure such as diffuse wall thickening and calcification were readily identified; however, the resolution of the transducers was not high enough accurately to measure wall dimensions in normal coronary arteries. Coefficient of variation measurements for intra and inter observer variability $(5 \cdot 2 \%$ and $6.9 \%$ respectively) showed excellent reproducibility. The technique was accurate in identifying atherosclerotic lesions, imaging arteries distal to an occlusion, locating deeply sited arteries, and identifying complete obliteration of an artery.

Intraoperative video playback and transducer miniaturisation may minimise problems caused by cardiac movement and restricted access. With these developments intraoperative assessment of coronary artery disease may become a real possibility.
\end{abstract}

High frequency epicardial echocardiography directly images the coronary artery lumen and wall. Intraoperative assessment of coronary artery anatomy by this technique may help to identify optimal sites for anastomoses by showing the coronary artery tree distal to the occluded segments. In addition, it may prove possible to identify stenotic lesions and perhaps even disease not detected at coronary angiography. To assess the accuracy and reliability of high frequency epicardial echocardiography we studied pressure perfused human hearts and compared the results with the histopathological examination.

Patients and methods

Human hearts were obtained at necropsy (eight hearts) or at orthotopic transplantation (two hearts). The coronary arterial tree was fixed with formalin at physiological pressure by the method described by Thomas and Davies. ${ }^{1}$ This method fixes the epicardial coronary arteries in a distended state so that they have the same shape and size as in life.

\section{ULTRASOUND EQUIPMENT}

Five hearts were studied with a Diasonics CV 250 unit and $10 \mathrm{MHz}$ small parts/vascular transducer. The $10 \mathrm{MHz}$ transducer measures $15 \mathrm{~cm}$ long, $5 \mathrm{~cm}$ wide, and $2.5 \mathrm{~cm}$ deep approximately. It has a depth of field of $3-4 \mathrm{~cm}$ and the imaging crystal is $13 \mathrm{~mm}$ in diameter with a built-in fluid offset. The phantom point lateral and axial resolution of the transducer are $0.8 \mathrm{~mm}$ and $0.3 \mathrm{~mm}$ respectively. We then studied another five hearts with a Vingmed/ Sonotron CFM 750 unit and $7.5 \mathrm{MHz}$ duplex transducer when it became available. This transducer has a contact surface of $4 \mathrm{~cm} \times$ $1.5 \mathrm{~cm}$ approximately and is $11 \mathrm{~cm}$ long. It has a built-in standoff and the axial resolution of this transducer operating at a frequency of $6.2 \mathrm{MHz}$ is $<0.5 \mathrm{~mm}$

\section{ULTRASOUND TECHNIQUE}

The hearts were immersed in a water tank and any air bubbles present eliminated by compression of the arteries under water. Imaging was then performed by one operator who was unaware of the presence of coronary atherosclerosis. The handheld transducer was placed over the epicardial surface of the heart and moved along the course of the artery being imaged to obtain longitudinal and cross sectional images. Simultaneous videotape recording was performed for analysis later. Ultrasound measurements were made on freeze frame images by internal electronic calipers. Measurements were confined to high quality images. The location along the coronary artery from which the echocardiographic image and measurements were obtained was marked with a metal staple in the adjacent epicardium. For the pathological measurements we used calipers to measure directly the arterial lumen of the marked arterial segments. Ultrasound measurements of wall thickness were compared with measurements on histological sections from paraffin processed transverse cut blocks. The intra and inter observer variabilities of high frequency epicardial echocardiography were measured to assess the reproducibility of the technique. Thirty randomly chosen images, 15 from each transducer, were reanalysed by the same
Correspondence to Dr A Kenny, Regional Hospital, Papworth Everard, Cambridge CB3 8RE

Accepted for publication 16 January 1991 


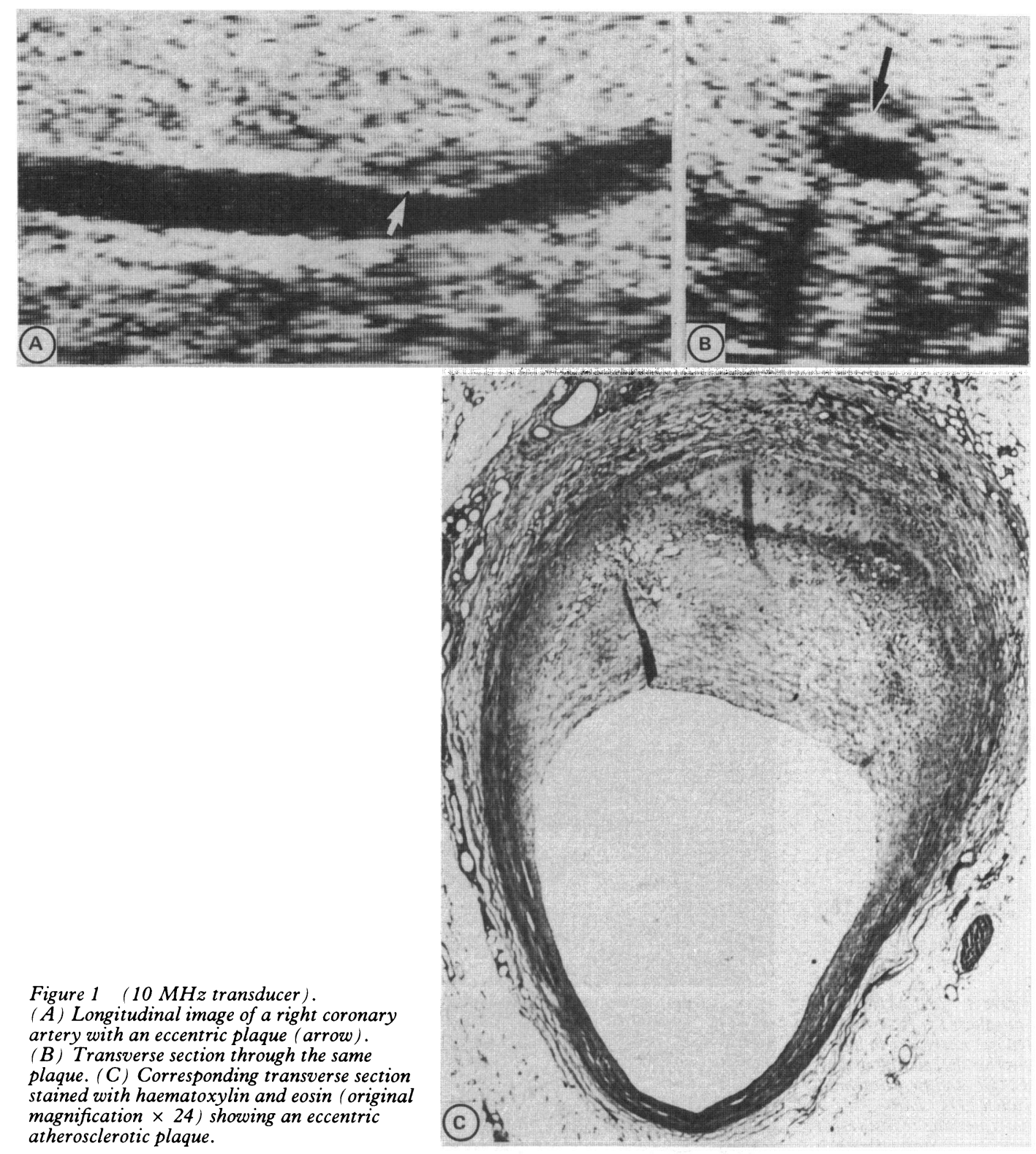

observer two weeks later. Another observer analysed the same 30 images independently.

\section{STATISTICAL ANALYSIS}

Agreement between ultrasound and pathological measurements of vessels was expressed as the mean plus or minus two standard deviations of the differences between the two methods. Intra and inter observer variability were assessed by the coefficient of variation.

\section{Results}

VISUALISATION OF CORONARY ARTERIES

Thirty six coronary arteries were studied in 10 hearts ( 14 with the $10 \mathrm{MHz}$ and 22 with the $7.5 \mathrm{MHz}$ transducer). The luminal diameter ranged from $0.7 \mathrm{~mm}$ to $5.0 \mathrm{~mm}$.

The right coronary artery was successfully imaged in eight hearts (figs 1 and 2). The right coronary artery was not imaged in two hearts: in one because perfusion fixation had resulted in collapse of the artery and in the other because of occlusion along the length of the artery which was confirmed at dissection.

The left anterior descending artery was visual- ised from the bifurcation of the left main coronary artery to the cardiac apex in eight hearts. The major diagonal branches and septal branches of the left anterior descending artery were also imaged (figs 3, 4, and 5). The left anterior descending coronary artery was noted to be occluded in the mid-segment in two hearts and this was confirmed at dissection. It was possible to image by ultrasound the artery distal to the occluded segment in both these hearts (figs $3 \mathrm{E}$ and $5 \mathrm{E}$ ). In one of these cases the artery distal to the occlusion was a bridged intramyocardial vessel and this was easily located with ultrasound (fig 3E).

The circumflex artery was imaged with the $7 \cdot 5$ $\mathrm{MHz}$ transducer in four hearts. This artery was not imaged in one heart because of occlusion along its length; this was confirmed at dissection. The circumflex artery was imaged in two of the five hearts by the $10 \mathrm{MHz}$ transducer. A first obtuse marginal branch of the circumflex coronary artery was also imaged. We did not image the circumflex coronary artery in two transplant recipient hearts because it had been transected. The circumflex coronary artery was occluded along its length in the fifth heart. 
Figure $2 \quad(7.5 \mathrm{MHz}$ transducer). (A) Normal right coronary artery with conus branch ( $C$ ) and $a$ line which may represent arterial wall (arrow).

(B) Normal right coronary artery in atrioventricular sulcus. coronary artery with right (arrow). RCA, right coronary artery. (C) Normal right ventricular branch
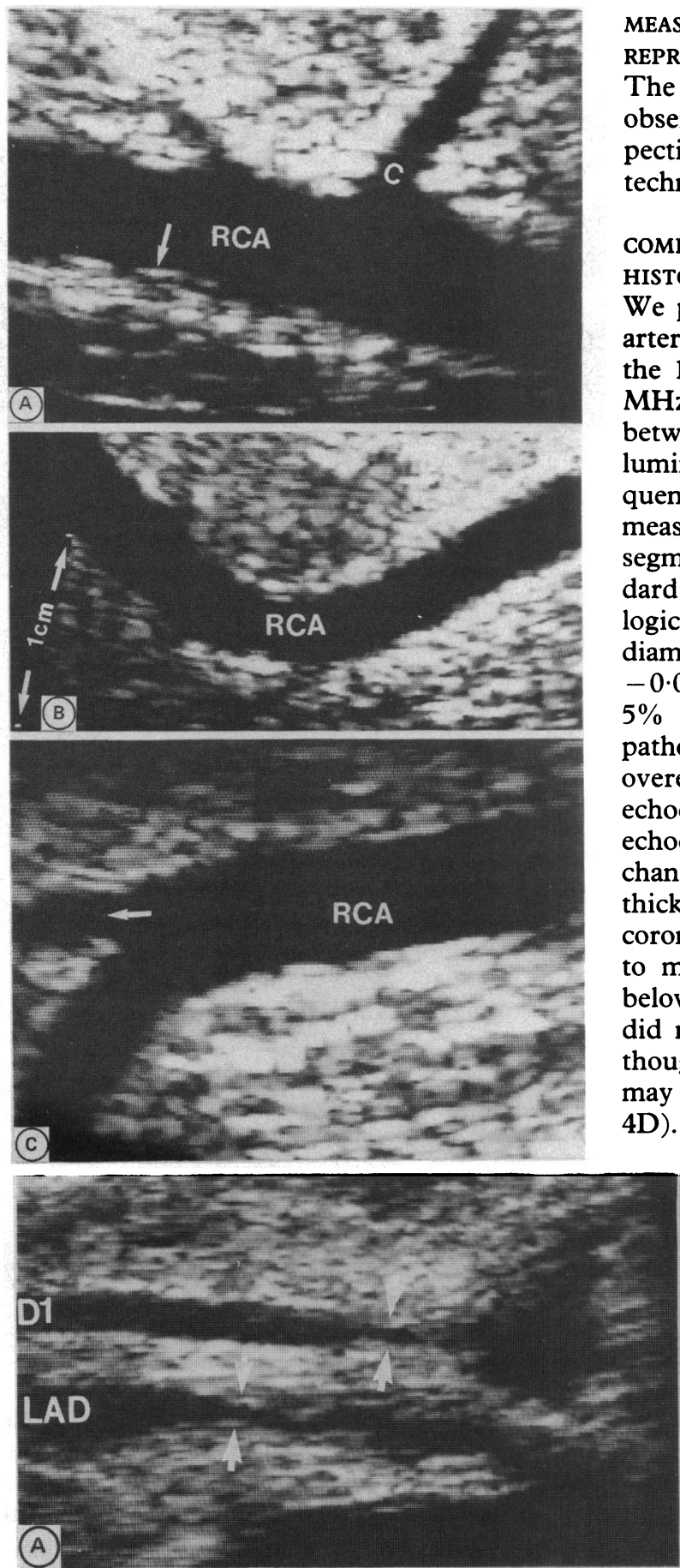
left anterior descending artery (arrows). (D) $A$ severely diseased left anterior descending artery with thickened wall (black arrow) and irregular lumen that eventually becomes occluded ( $\mathrm{O}$ ). (E) $A$ site $2 \mathrm{~cm}$ distal to the obstruction shows a deeply sited, thin walled normal myocardial bridged segment of the same artery (white arrow).

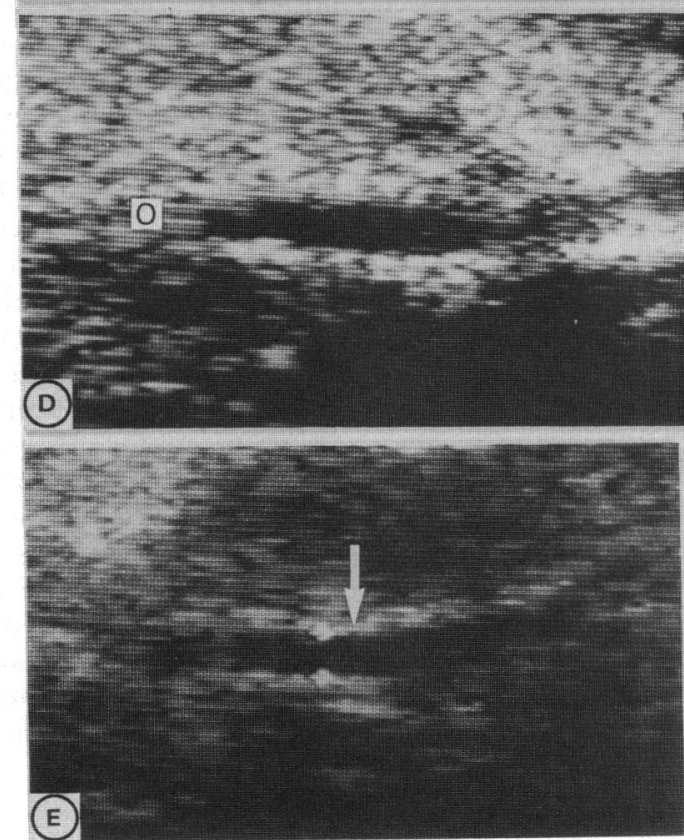

MEASUREMENT RELIABILITY AND

REPRODUCIBILITY

The coefficients of variation for intra and inter observer measurements $(5.2 \%$ and $6.9 \%$ respectively) showed the reproducibility of the technique was acceptable.

\section{COMPARISON OF ULTRASOUND AND}

HISTOPATHOLOGICAL MEASUREMENTS

We performed 59 measurements of coronary artery luminal diameter $(0 \cdot 7-5 \cdot 0 \mathrm{~mm})$ (33 with the $10 \mathrm{MHz}$ transducer and 26 with the $7 \cdot 5$ $\mathrm{MHz}$ transducer). There was close agreement between measurements of coronary artery luminal diameter determined by high frequency epicardial echocardiography and measurements made when the corresponding segments of arteries were dissected. The standard deviation of differences between pathological and ultrasonic measurements of luminal diameter was $0.12 \mathrm{~mm}$ with a mean difference of $-0.01 \mathrm{~mm}$. There was therefore a less than $5 \%$ chance of either underestimating the pathological dimension by $0.25 \mathrm{~mm}$ or of overestimating it by $0.22 \mathrm{~mm}$ by the use of echocardiography. High frequency epicardial echocardiography readily identified qualitative changes in wall structure such as diffuse wall thickening and calcification (fig 3D). In normal coronary arteries, however, it was not possible to measure the arterial wall because it was below the resolution of both transducers. We did note a line adjacent to the lumen which though it was too thick to be the endothelium may be the normal arterial wall (figs $2 \mathrm{~A}$ and 4D).

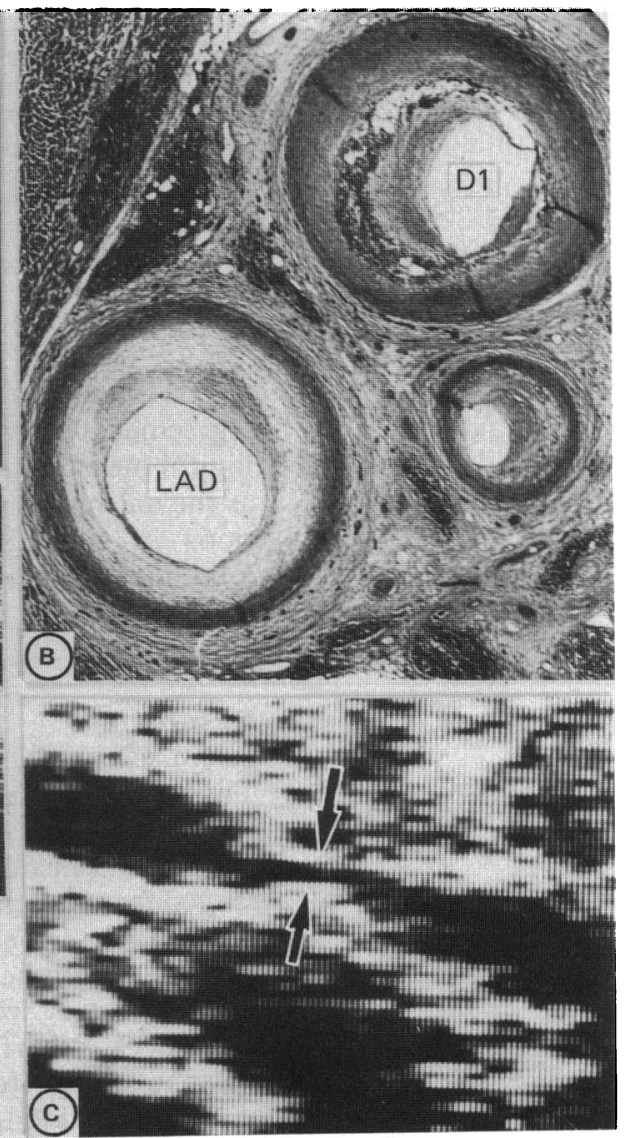


Figure $4 \quad(7.5 \mathrm{MHz}$ transducer). (A) Normal left anterior descending artery ( $L A D)$ and first diagonal branch (D1). (B) Normal left anterior descending artery with first and second (D2) diagonal branches. (C) Normal left anterior descending artery with two septal branches (S). (D) Normal left anterior descending artery with clearly defined line which may represent arterial wall (arrows).

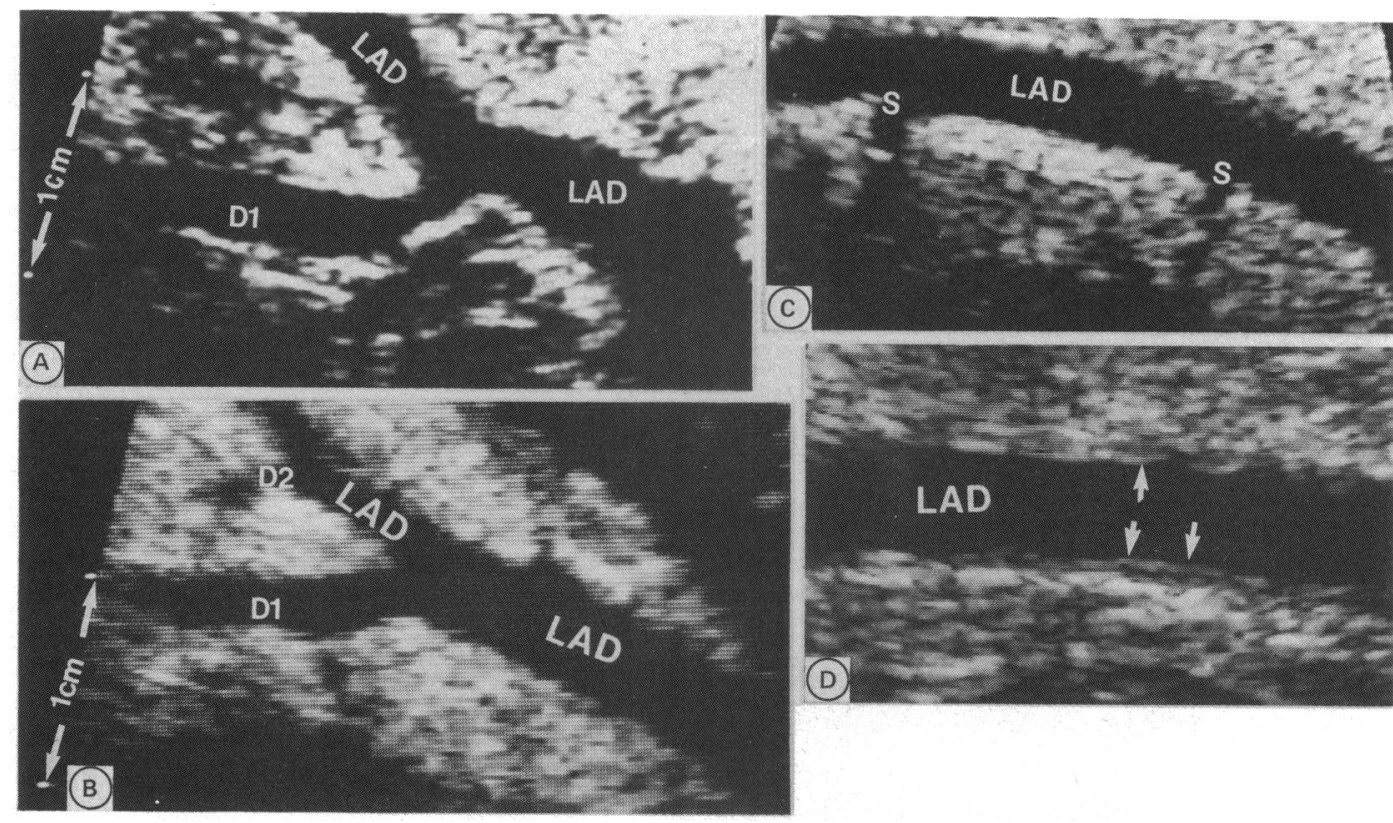

DETECTION OF CORONARY ATHEROSCLEROSIS All lesions detected by ultrasound were examined by histological section. Ultrasonographically normal segments of coronary arteries were also sectioned. There was complete agreement between the two methods with respect to the presence or absence of lesions.

\section{Discussion}

Coronary angiography, which is the standard method of evaluating coronary artery disease, has some limitations. Pathological and physiological studies suggest that coronary angiography underestimates the extent and severity of coronary artery disease. ${ }^{2-4}$ Complete occlusion of an artery at angiography limits information on the distal coronary arterial bed and its suitability for insertion of bypass grafts. Visually estimated percentage diameter narrowing on coronary angiography as a measure of the severity of stenosis is not universally accepted, especially in lesions of intermediate severity. ${ }^{56}$ These limitations of coronary angiography suggest that the preoperative information provided to the surgeon by angiography may not always be optimal. Imaging of coronary arteries with a commercial high frequency epicardial transducer may therefore provide useful information supplementary to the coronary angiogram.

High frequency epicardial echocardiography with a high resolution transducer to image the coronary arteries was first described by Sahn $e t$ $a l$ in $1982 .{ }^{7}$ Epicardial placement of the transducer allows longitudinal and cross sectional imaging of the coronary arterial lumen and wall; whereas angiography provides a longitudinal image of contrast in the arterial lumen and only provides an image of the arterial wall if calcification is present. Previous studies have validated the accuracy of high frequency epicardial echocardiography in assessing the luminal diameter of the coronary artery and the wall dimensions in living animal models. ${ }^{8-10}$ The technique has not been validated with either a $10 \mathrm{MHz}$ or $7.5 \mathrm{MHz}$ transducer.
McPherson et al are the only other group to have validated high frequency epicardial echocardiography by studying human hearts in vitro. ${ }^{11}$ They established the accuracy of a 12 $\mathrm{MHz}$ transducer in assessing coronary artery luminal and wall measurements in vivo and also in vitro using five human postmortem hearts. However, the ultrasound measurements were performed on the pressure perfused hearts before formalin fixation and compared with histological measurements on formalin and paraffin processed sections. The histological measurements are therefore subject to fixation artefacts. Arterial shrinkage occurs and this technique has been shown to alter measurements by up to $10 \% .^{12}$ We performed ultrasound measurements on the formalin fixed, pressure perfused heart and subsequently made pathological measurements at dissection. In this way we avoided potential errors in comparing ultrasound measurements of luminal diameter with measurements on histological sections with possible fixation and shrinkage artefacts.

We found the technique to be accurate and reliable for measuring coronary artery luminal diameter. Though the resolution of the transducers was not sufficient accurately to identify the interface between the arterial wall and adjacent epicardium in thin normal arterial walls, qualitative changes in wall structure and calcified and fibrotic plaques were readily identified (figs 1, 3A, 5A, and 5B). Visualisation of a coronary artery distal to an occlusion, which may be difficult to assess with angiography, was also possible with high frequency epicardial echocardiography (figs $3 \mathrm{E}$, and $5 \mathrm{~F}$ ). This is likely to be useful in identifying a suitable site for graft insertion. When an artery was not located by ultrasound pathological examination confirmed that the artery was occluded along its entire length. This may be useful during operation because it may prevent the unnecessary delay of searching for an obliterated artery. Accurate measurement of luminal diameter and delineation of atherosclerosis may also identify arteries that are diffusely 

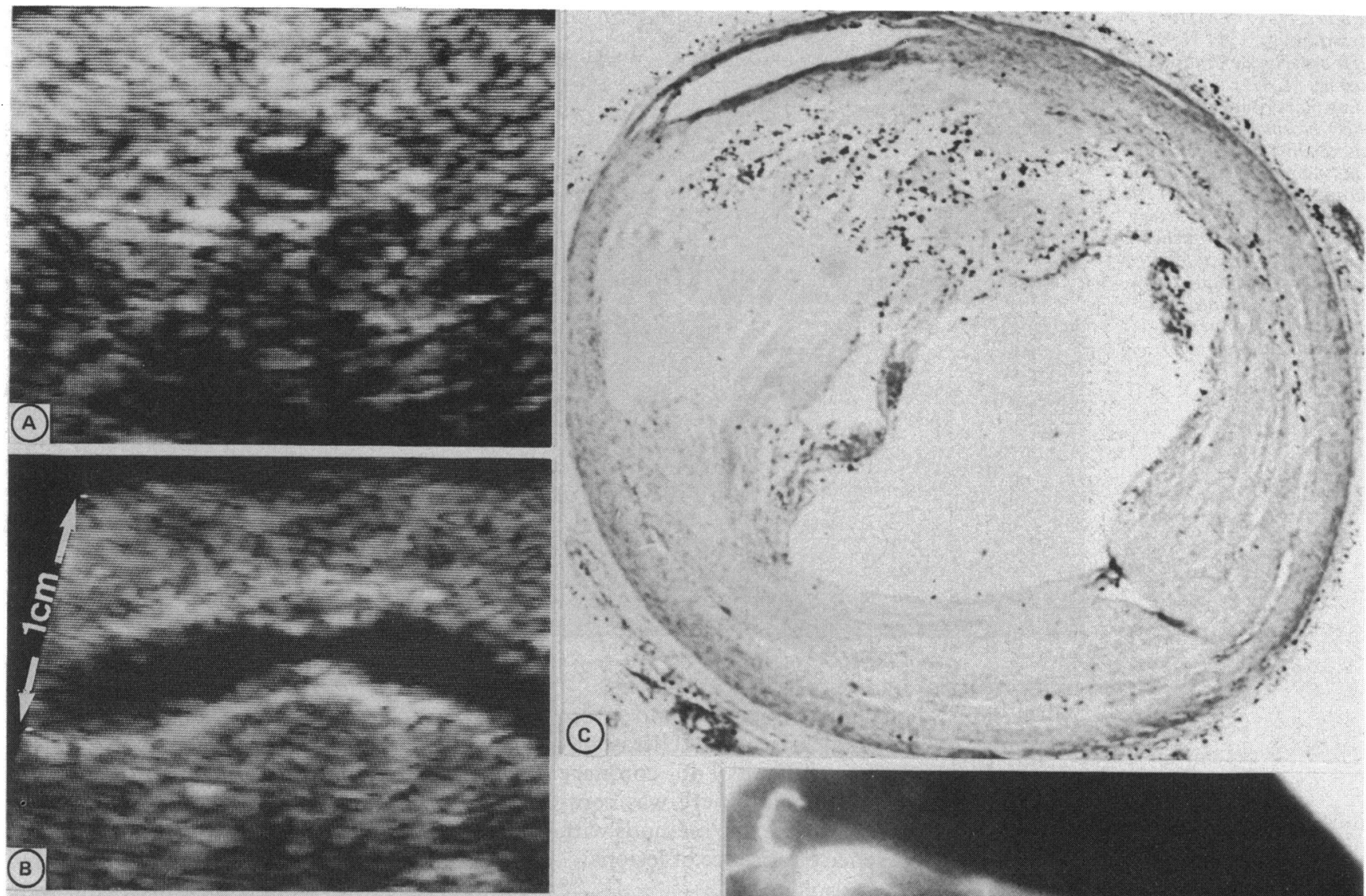

(B)
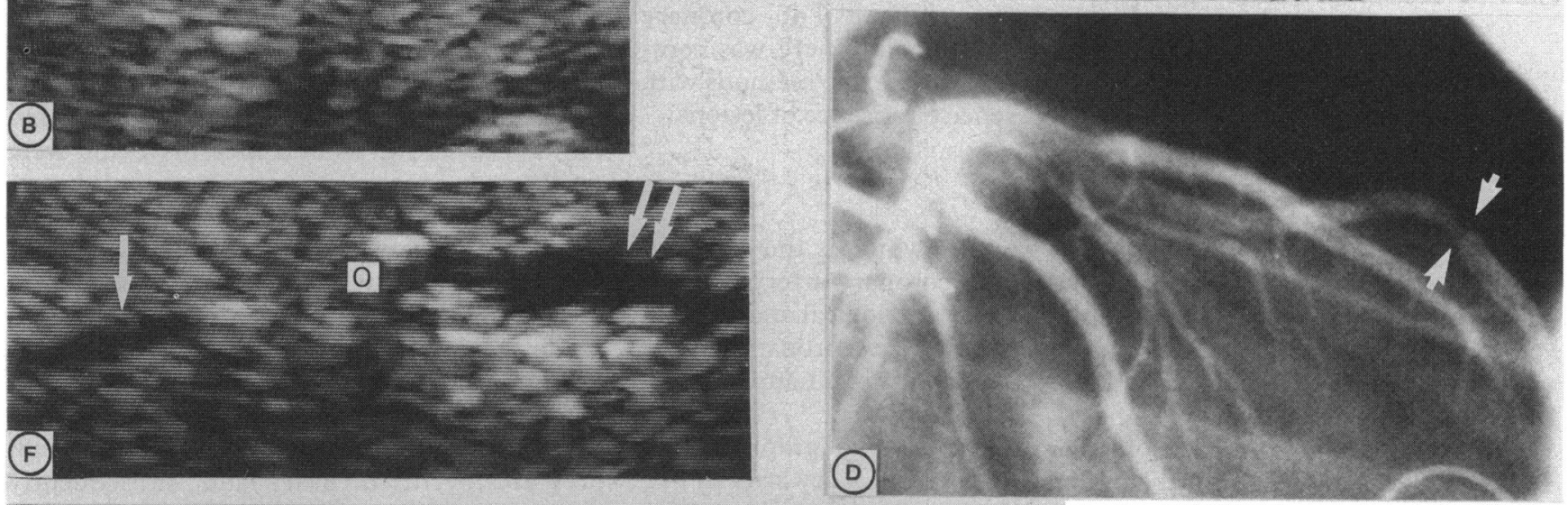

(D)

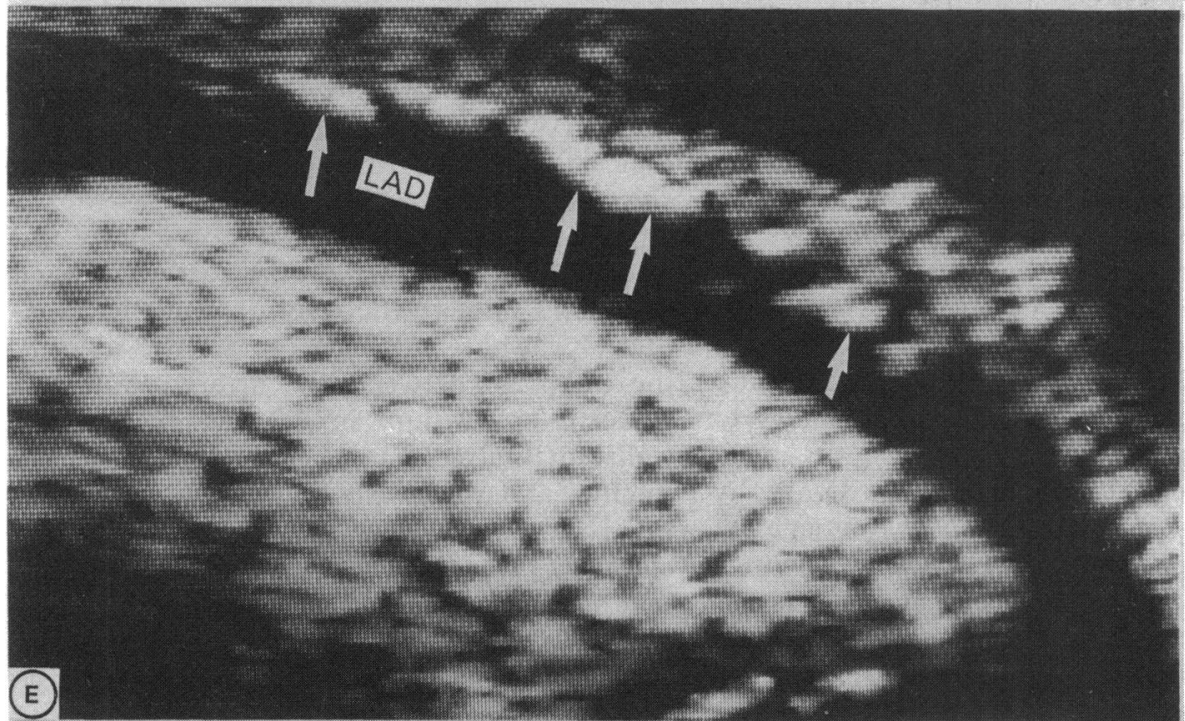

Figure $5 \quad(7.5 \mathrm{MHz}$ transducer $)$

Transverse $(A)$ and longitudinal $B$

images of a discrete stenotic lesion in a mid left anterior descending artery.

(C) Corresponding transverse section stained with haematoxylin and eosin

(original magnification $\times 27$ ) shows concentric intimal thickening.

(D) Coronary angiogram taken two weeks before death (lesion arrowed) is also

shown. (E) Left anterior descending artery with atheromatous deposits along superior wall (arrows). (F) Severely diseased left anterior descending artery (double arrow) with occlusion (O) and patent artery distal to occlusion (arrow).

diseased and too small to accept a graft. We also showed that deeply sited arteries can be readily identified (fig 3E). Both transducers produced satisfactory images, and though one would expect the $10 \mathrm{MHz}$ transducer to have better resolution than the $7.5 \mathrm{MHz}$ transducer, we found that the $7.5 \mathrm{MHz}$ transducer produced qualitatively better images. The $7.5 \mathrm{MHz}$ transducer is a more recently developed transducer and its image quality has been improved by recent technical advances. The smaller $7 \cdot 5$ $\mathrm{MHz}$ transducer will also allow Doppler examination of the coronary blood flow, but its size will limit examination of the coronary 
artery tree in vivo to the left anterior descending and proximal right coronary arteries.

High frequency epicardial echocardiography with a $7.5 \mathrm{MHz}$ or $10 \mathrm{MHz}$ transducer accurately and reproducibly measured coronary artery luminal diameter, detected qualitative changes in wall structure, and delineated stenotic lesions. In addition, it located deeply sited vessels, visualised an artery distal to an occlusion, and showed whether an artery is completely obliterated.

We have performed several preliminary studies in patients undergoing cardiac surgery. Cardiac movement and restricted access have proved to be the main obstacles to intraoperative imaging of coronary arteries. Videotape recording and rapid playback facilities have enabled detailed analysis of arteries intermittently visualised during the cardiac cycle. We are about to assess a new 7.5 $\mathrm{MHz}$ finger profile transducer that should greatly improve access to the right coronary and circumflex arteries.

1 Thomas AC, Davies MJ. The demonstration of cardiac pathology using perfusion-fixation. Histopathology 1985; 9:5-19.

2 Arnett EN, Isner JM, Redwood DR, et al. Coronary artery narrowing in coronary heart disease: comparison of cine- angiographic and necropsy findings. Ann Intern Med 1979;

3 Vlodaver Z, Frech R, Van Tassel RA, Edwards JE. Correlation of the antemortem arteriogram and the postmortem specimen. Circulation 1973;47:162-9.

4 White CW, Wright CB, Doty DB, et al. Does visual interpretation of the coronary arteriogram predict the physiologic importance of a coronary stenosis? $N$ Engl $J$ Med 1984;310:819-24.

5 Marcus ML, Skorton DJ, Johnson MR, Collins SM, Harrison DJ, Kerber RE. Visual estimates of percent diameter coronary stenosis: "a battered gold standard". J Am Coll Cardiol 1988;11:882-5.

6 Gould KL. Percent coronary stenosis: battered gold standard, pernicious relic or clinical practicality? $\mathrm{J} \mathrm{Am}$ Coll Cord

7 Sahn DJ, Barret-Boyes BG, Graham K, et al. Ultrasonic imaging of the coronary arteries in open-chest humans: evaluation of coronary atherosclerotic lesions during cardiac surgery. Circulation 1982;66:1034-44.

8 McPherson D, Armstrong M, Marcus M, Kieso R, Megan $M$, Kerber R. Evaluation of the coronary arterial wall and lumen by high frequency 2-dimensional epicardial echocardiography: comparison with histologic measurements [Abstract]. J Am Coll Cardiol 1984;3:565.

9 McPherson DD, Kieso RE, Marcus ML, Kerber RE. In vivo validation of high frequency epicardial echocardiography for coronary arterial measurements. Circulation 1984;70(suppl 11):11-393.

10 McPherson DD, Armstrong $\mathrm{M}$, Rose $\mathrm{E}$, et al. High frequency epicardial echocardiography assessment of coronary arteries: further validation [Abstract]. $\mathrm{J} \mathrm{Am} \mathrm{Coll}$ Cardiol 1985;5:387.

11 McPherson DD, Armstrong M, Rose E, et al. High frequency epicardial echocardiography for coronary artery evaluation: in vitro and in vivo validation of arteria lumen and wall thickness measurements. $J \mathrm{Am} C o l l$ Cardiol 1986;8:600-6.

12 Bond MG, Insull W Jr, Glagov S, Chandler AB, Cornhill $\mathrm{JF}$, eds. Clinical diagnosis of atherosclerosis-quantitative methods of evaluation. New York: Springer-Verlag, 1983 11-35, 265-82, 283-303. 